\title{
NMDA Receptor Enhances Correlation of Spontaneous Activity in Neonatal Barrel Cortex
}

\author{
${ }^{\circledR}$ Hidenobu Mizuno, ${ }^{1,2}{ }^{\circledR}$ Madhura S. Rao, ${ }^{1,2}$ Hiromi Mizuno, ${ }^{1,2}$ Takuya Sato, ${ }^{3}{ }^{\circledR}$ Shingo Nakazawa, ${ }^{3}$ and \\ (1) Takuji Iwasato ${ }^{3,4}$ \\ ${ }^{1}$ Laboratory of Multi-Dimensional Imaging, International Research Center for Medical Sciences (IRCMS), Kumamoto University, Kumamoto 860- \\ 0811, Japan, ${ }^{2}$ Graduate School of Medical Sciences, Kumamoto University, Kumamoto 860-0811, Japan, ${ }^{3}$ Laboratory of Mammalian Neural Circuits, \\ National Institute of Genetics, Mishima 411-8540, Japan, and ${ }^{4}$ Department of Genetics, SOKENDAI (The Graduate University for Advanced \\ Studies), Mishima 411-8540, Japan
}

Correlated spontaneous activity plays critical role in the organization of neocortical circuits during development. However, cortical mechanisms regulating activity correlation are still elusive. In this study, using two-photon calcium imaging of the barrel cortex layer 4 (L4) in living neonatal mice, we found that NMDA receptors (NMDARs) in L4 neurons are important for enhancement of spontaneous activity correlation. Disruption of GluN1 (Grin1), an obligatory NMDAR subunit, in a sparse population of L4 neurons reduced activity correlation between GluN1 knock-out (GluN1KO) neuron pairs within a barrel. This reduction in activity correlation was even detected in L4 neuron pairs in neighboring barrels and most evident when either or both of neurons are located on the barrel edge. Our results provide evidence for the involvement of L4 neuron NMDARs in spatial organization of the spontaneous firing activity of L4 neurons in the neonatal barrel cortex.

Key words: barrel cortex; in vivo two-photon calcium imaging; L4 neurons; NMDA receptor; sparse cell labeling; spontaneous activity correlation

\section{Significance Statement}

Precise wiring of the thalamocortical circuits is necessary for proper sensory information processing, and thalamus-derived correlated spontaneous activity is important for thalamocortical circuit formation. The molecular mechanisms involved in the correlated activity transfer from the thalamus to the neocortex are largely unknown. In vivo two-photon calcium imaging of the neonatal barrel cortex revealed that correlated spontaneous activity between layer four neurons is reduced by mosaic knock-out (KO) of the NMDA receptor (NMDAR) obligatory subunit GluN1. Our results suggest that the function of NMDARs in layer four neurons is necessary for the communication between presynaptic and postsynaptic partners during thalamocortical circuit formation.

Received Mar. 4, 2020; revised Dec. 9, 2020; accepted Dec. 14, 2020.

Author contributions: Hid.M. designed research; Hid.M., M.S.R., Hir.M., T.S., S.N., and T.I. performed research; Hid.M., T.S., and T.I. contributed unpublished reagents/analytic tools; Hid.M., M.S.R., T.S., S.N., and T.I. analyzed data; Hid.M. wrote the paper.

This work was supported by Japan Society for the Promotion of Science Grants-in-Aid for Scientific Research Grants JP16H06143 and 20K06876, the Takeda Science Foundation, the Uehara Memorial Foundation, the Ichiro Kanehara Foundation, the Senri Life Science Foundation, the Research Foundation for Opto-Science and Technology, the Naito Foundation, the Narishige Neuroscience Research Foundation, the Collaborative Research Project of Niigata University Brain Research Institute (2018-2906, 201926), and the National Institute of Genetics-Joint Research Grant 43 A2019 (to Hid.M.); and the Government of Japan's Ministry of Education, Culture, Sports, Science and Technology Grant-in Scientific Research on Innovation Areas "Dynamic Regulation of Brain Function by Scrap and Build System" JP16H06459 (to T.I.). We thank R. Koitabashi, M. Kanbayashi, and S. Kouyama for technical assistance.

S. Nakazawa's present address: Department of Basic Neurosciences, University of Geneva, Geneva 1211, Switzerland.

The authors declare no competing financial interests.

Correspondence should be addressed to Hidenobu Mizuno at hmizuno@kumamoto-u.ac.jp.

https://doi.org/10.1523/JNEUROSCI.0527-20.2020

Copyright $\odot 2021$ the authors

\section{Introduction}

Correlated spontaneous activity is important in the maturation of sensory neuronal circuits (Katz and Shatz, 1996; Sur and Rubenstein, 2005; Cang and Feldheim, 2013; Ackman and Crair, 2014). During visual cortical circuit development, waves of spontaneous action potentials spreading among retinal ganglion cells travel to the visual cortex and the superior colliculus (Meister et al., 1991; Wong et al., 1995; Hanganu et al., 2006; Ackman et al., 2012). Blockade of this patterned activity in the retina perturbs the proper formation of thalamocortical connections (Stryker and Harris, 1986; Huberman et al., 2006), suggesting that correlated spontaneous activity is important for precise circuit wiring of the visual cortex (Katz and Shatz, 1996; Sur and Rubenstein, 2005; Thompson et al., 2017). Synchronous spontaneous activity is also observed in the developing auditory and somatosensory systems (Tritsch et al., 2007; Golshani et al., 2009; Kandler et al., 2009; Kirkby et al., 2013; Mizuno et al., 2018a; Nakazawa et al., 2020). 
Layer 4 (L4) of the rodent somatosensory cortex has an array of "barrels" that correspond to the arrangement of whiskers on the face (Woolsey and Van der Loos, 1970; Petersen, 2007; Iwasato and Erzurumlu, 2018). The termini of thalamocortical axons from the ventral posteromedial nucleus are clustered in each barrel center; L4 neurons extend their dendrites toward the barrel center and receive inputs from the corresponding thalamocortical axon cluster (Woolsey and Van der Loos, 1970; Woolsey et al., 1975; Erzurumlu and Jhaveri, 1990; Erzurumlu and Kind, 2001; Fox, 2008; Iwasato, 2020; Rao and Mizuno, 2020). These characteristic circuits are formed by whisker and thalamic inputs during development (Woolsey and Wann, 1976; Narboux-Nême et al., 2012; Li et al., 2013; Antón-Bolaños et al., 2019). Electrophysiological and imaging studies have reported spatiotemporal patterns of activity in the developing barrel cortex (Khazipov et al., 2004; Golshani et al., 2009; Yang et al., 2009, 2013; Tiriac et al., 2012; Akhmetshina et al., 2016). We recently reported that in the neonatal barrel cortex L4 neurons within the same barrel fire synchronously, making a "patchwork" pattern of spontaneous activity corresponding to the barrel map, which is also present in the thalamus (Mizuno et al., 2018a). Another recent study disclosed that activity synchronization in the prenatal thalamus is involved in circuit formation in the barrel cortex (Antón-Bolaños et al., 2019). However, the molecular mechanisms that govern the transfer of correlated activity from the thalamus to L4 neurons remain unknown.

Previous studies have revealed numerous molecules that are involved in barrel cortex circuit formation (Erzurumlu and Kind, 2001; Inan and Crair, 2007; Wu et al., 2011), and some of these molecules may also be involved in correlation of spontaneous activity. In this study, we assessed the role of NMDA-type glutamate receptor (NMDAR) in activity correlation. NMDARs are involved in Hebbian-type plasticity observed at the thalamocortical synapses of neonatal rodents (Crair and Malenka, 1995) and play key roles in central nervous system development (Cline and Constantine-Paton, 1990; Sin et al., 2002; Wong and Ghosh, 2002), including circuit refinement in the barrel cortex L4 (Iwasato et al., 1997, 2000; Datwani et al., 2002; Lee et al., 2005; Arakawa et al., 2014). In addition, single-cell knock-out (KO) of GluN1 (NR1) or GluN2B (NR2B), the obligatory subunits of NMDAR in the neonatal cortex, in L4 neurons disrupts their biased dendritic patterns (Espinosa et al., 2009; Mizuno et al., 2014).

In this study we used in vivo two-photon calcium imaging to analyze neural activity correlation in neonatal barrel cortex L4 neurons following $\mathrm{KO}$ of GluN1 in a subset of these neurons. We found that the correlation of activity was reduced in the absence of NMDARs. Our findings highlight the important role of NMDARs for the functional maturation of cortical L4 neurons.

\section{Materials and Methods}

Animals

All experiments were conducted in accordance with the guidelines for animal experimentation of the Kumamoto University and the National Institute of Genetics (NIG) and approved by the animal experimentation committees.

TCA-RFP; Grinlfloxed mice of either sex were acquired by crossing TCA-RFP male mice (Mizuno et al., 2018a) and Grinlfloxed female mice (Iwasato et al., 2000). TCA-RFP mice [produced in the C57BL/6 (B6)/C3H genetic background] were backcrossed one to three times with the ICR mouse strain. Grinlfloxed mice (produced in the 129 genetic background and backcrossed $>20$ times with B6) were backcrossed 10-15 times with ICR.
Plasmids construction and supernova system

To generate the pK127:CAG-loxP-STOP-loxP-LacZ-ires-tTA-WPRE plasmid, the $\beta$-galactosidase sequence was excised from the pNASS $\beta$ vector (Clontech) with NotI, and inserted into the SalI/EcoRV sites of the pK038:CAG-loxP-STOP-loxP-EGFP-ires-tTA-WPRE (Luo et al., 2016) by blunt-end ligation. To generate the pK145:CAG-Flpe, the Flpe sequence was excised from the pK036:TRE-Flpe-WPRE (Luo et al., 2016) and inserted into the BamHI/NotI sites of the pK025:CAGTurboRfP (Luo et al., 2016). To generate the pK273:CAG-loxPSTOP-loxP-CyRFP-ires-tTA-WPRE, CyRFP1 (Laviv et al., 2016) was inserted into the SalI/EcoRV sites of the pK038. For generation of the pM001:CAG-FRT-STOP-FRT-GCaMP6s, the GCaMP6s sequence was excised from the pK175:CAG-loxP-STOP-loxP-GCaMP6s-ires-tTAWPRE (Mizuno et al., 2018a) and inserted into the SalI/NotI sites of the pK037:CAG-FRT-STOP-FRT-RFP-ires-tTA-WPRE (Luo et al., 2016).

For Supernova-GCaMP6s/LacZ, DNA solution containing pK031: TRE-Cre (Mizuno et al., 2014; $10 \mathrm{ng} / \mu \mathrm{l})$, pK175 (1 $\mu \mathrm{g} / \mu \mathrm{l})$, and pK127 $(1 \mu \mathrm{g} / \mu \mathrm{l})$ was used. To discriminate between GluN1KO neurons and control neurons within the same animal, DNA solution containing

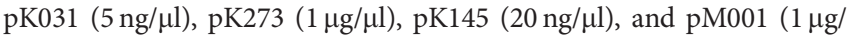
$\mu \mathrm{l})$ was used.

\section{In utero electroporation}

In utero electroporation was conducted as previously described (FukuchiShimogori and Grove, 2001; Saito and Nakatsuji, 2001; Tabata and Nakajima, 2001; Mizuno et al., 2007, 2010). Pregnant mice were anesthetized at embryonic day (E)14 (between 10 A.M. and 2 P.M.) with a combination of sodium pentobarbital ( $50 \mathrm{mg} / \mathrm{kg}$ body weight) and isoflurane gas $(1.0-1.5 \%$ in air). A midline laparotomy was conducted to expose the uterus, and a pulled glass capillary was used to inject DNA into embryos. Square electric pulses $(40 \mathrm{~V}, 50 \mathrm{~ms}, 1 \mathrm{~Hz})$ were delivered to embryos three to five times using an electroporator (CUY21SC or NEPA21, NepaGene) and forceps-type electrodes (CUY650P5, NepaGene). After electroporation, the uterus was repositioned, and the abdominal wall and skin were sutured. Mice were allowed to recover on a heater $\left(37^{\circ} \mathrm{C}\right)$.

\section{Histology and confocal microscopy}

For histologic analyses, mouse brains were fixed with $4 \%$ paraformaldehyde in phosphate buffer (PB) overnight, and then transferred to $30 \%$ sucrose in PB for $1 \mathrm{~d}$. Tangential brain sections $(100 \mu \mathrm{m}$ thick) were made with a freezing microtome (Yamato), then permeabilized and blocked in $0.2 \%$ Triton X-100/5\% normal goat serum (Sigma) in PB. Mouse anti-LacZ (1:1000, Promega) and Alexa Fluor 488-conjugated goat anti-mouse IgG (1:1000, Invitrogen) antibodies were used to visualize LacZ signals in electroporated neurons. Rabbit anti-vGluT2 (1:1000, Synaptic Systems) and Alexa Fluor 568-conjugated goat anti-mouse IgG (1:1000, Invitrogen) antibodies were used to visualize the barrel arrangement in Grinlfloxed mice. 4',6-diamidino-2-phenylindole (DAPI) was used to evaluate cortical architecture. Fluorescent images were obtained using a TCS SP5 or a SP8LS confocal microscope (Leica).

\section{Two-photon microscopy}

Craniotomies were performed for intravital imaging as previously described (Mizuno et al., 2014, 2018a,b). Pups were anesthetized with isoflurane (0.7-1.5\%), and the skull overlying the barrel field was removed with a razor blade, leaving the dura intact. A thin layer of $1 \%$ low-melting point agarose (Sigma) in cortex buffer $(125 \mathrm{~mm} \mathrm{NaCl}, 5 \mathrm{~mm}$ $\mathrm{KCl}, 10 \mathrm{~mm}$ glucose, $10 \mathrm{~mm}$ HEPES, $2 \mathrm{~mm} \mathrm{CaCl}_{2}$, and $2 \mathrm{~mm} \mathrm{MgSO}_{4}, \mathrm{pH}$ 7.4; Holtmaat et al., 2009) was applied to cover the exposed dura, then the skull window was sealed with a 3-mm-diameter round cover glass (Matsunami) and secured in place with dental cement. A custom titanium bar $(\sim 30 \mathrm{mg})$ was attached to the area adjacent to the cranial window. Following surgery, pups were allowed to recover on a heater.

In vivo calcium imaging was conducted under an unanesthetized condition as previously described (Mizuno et al., 2018a). The body temperature of pups was maintained with the use of a heating pad. In vivo observations were conducted using an LSM 7MP multiphoton microscope (Zeiss) with a Mai Tai eHP DeepSee titanium-sapphire laser 
A

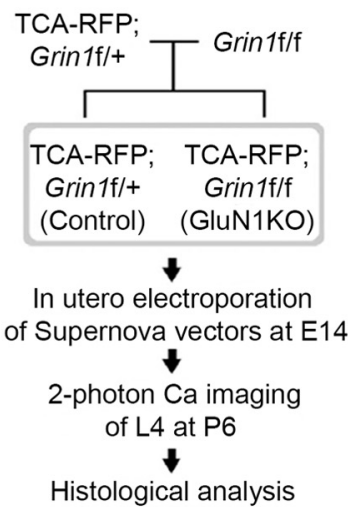

B

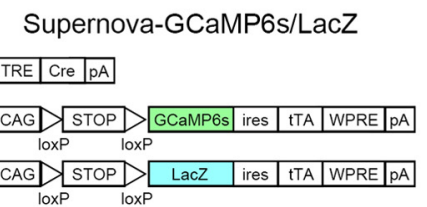

C

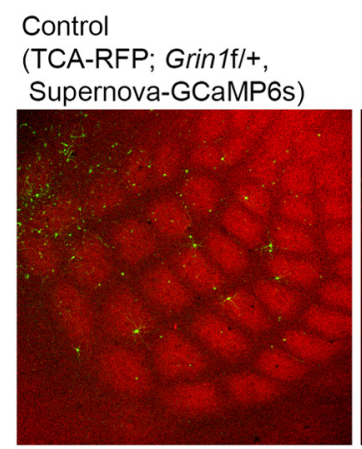

GluN1KO

(TCA-RFP; Grin1f/f,

Supernova-GCaMP6s)

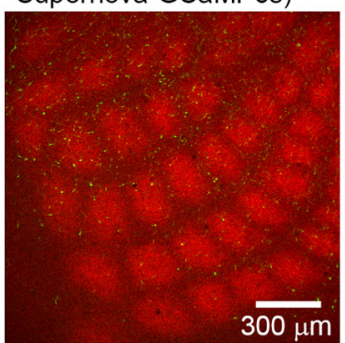

D

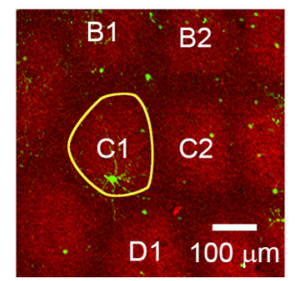

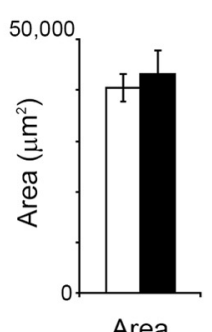

Area

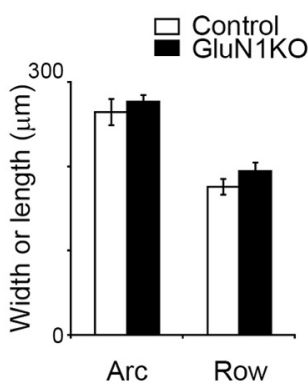

Figure 1. Sparse K0 of GluN1 in L4 neurons does not affect thalamocortical terminal clustering. $\boldsymbol{A}$, Experimental schema for in vivo calcium imaging and subsequent histologic analysis. $\boldsymbol{B}$, Schematic of the Supernova-GCaMP6s/LacZ vectors for in utero electroporation. TRE, tetracycline response element; pA, polyadenylation signal; CAG, CAG promoter; ires, internal ribosome entry site; tTA, tetracycline transactivator; WPRE, woodchuck hepatitis virus posttranscriptional regulatory element. $\boldsymbol{C}$, Representative confocal images of tangential sections from TCA-RFP; Grin1floxed/+ and TCA-RFP; Grin1floxed/floxed mice at P6. Supernova-GCaMP6s-labeled neurons in TCA-RFP; Grin1floxed/+ and TCA-RFP; Grin1floxed/floxed mice are control and GluN1K0 neurons, respectively. D, The area, width (row), and length (arc) of (1 barrel (yellow line in the left panel) visualized as a thalamocortical axon cluster were quantified at P6. Number of animals: control, 7; GluN1K0, 4.

(Spectra-Physics) at $940 \mathrm{~nm}$ and a $20 \times$ objective lens $(1.05 \mathrm{NA})$, or a SP8 MP multiphoton microscope (Leica) with a Alcor 920-2W laser (Spark Lasers) and a $25 \times$ objective lens (0.95 NA). GCaMP and RFP were simultaneously excited and emitted fluorescence was filtered (500-550 nm for GCaMP and 575-620 nm for RFP). To acquire calcium transients from L4 neurons, time-lapse images were obtained at $0.65-1.3 \mathrm{~Hz}(512 \times 512$ pixels $)$.

\section{Examination and quantification of calcium imaging data}

The obtained time-lapse images from in vivo two-photon observation were assessed using ZEN software (Zeiss), LasX software (Leica), Microsoft Excel, and ImageJ software with Fiji (Schindelin et al., 2012) as previously described (Ikezoe et al., 2012; Tsutsumi et al., 2015; Mizuno et al., 2018a), with minor alterations. To examine fluorescence changes in the GCaMP signals in single cells, $\mathrm{dF} / \mathrm{F}$ wave, expressed as $\mathrm{dF} / \mathrm{F}=\left(\mathrm{F}-\mathrm{F}_{0}\right) /\left(\mathrm{F}_{0}-\mathrm{F}_{\mathrm{b}}\right)$, where $\mathrm{F}_{0}$ is the baseline signal in the absence of calcium transients and $\mathrm{F}_{\mathrm{b}}$ is the background fluorescence, was computed. To obtain F, a $20-\mu \mathrm{m}$-diameter circle (region of interest; ROI) was centered of each GCaMP-labeled cell. A threshold, the mean + SD of the $\mathrm{F}$ wave, was calculated, and the $\mathrm{F}$ wave below the threshold was averaged to obtain $\mathrm{F}_{0}$. To obtain $\mathrm{F}_{\mathrm{b}}$, a square box $(18 \times 18=324$ pixels that approximately equal to the pixel numbers in the ROI) scan was conducted on the first image of the movie, and the minimum value of the scan was calculated. Calcium transient with a peak higher than the threshold were considered as an "event." For comparisons between the GluN1 heterozygous control cell pairs and GluN1KO cell pairs (Figs. 1-6), data analyses were performed under strict genotype-blind conditions, and the genotypes were revealed only after all experiments and analyses were completed. For measurements of the event frequency, L4 neurons located in the barrel center were used. To distinguish L4 neurons on the barrel edge and from those in the barrel center (Figs. $4 D$, $5 D$ ), we defined the edge of barrel with the use of the fluorescent signal of thalamocortical axons as previously described (Mizuno et al., 2014). We defined L4 neurons with an apical dendrite $\geq 20 \mu \mathrm{m}$ as $\mathrm{AD}^{+}$neurons, and all others as $\mathrm{AD}^{-}$neurons.

\section{Statistics}

Values are presented as means \pm standard error (SE). Statistical analyses were conducted using Microsoft Excel and SPSS Statistics Base. The significance of the differences was analyzed by two-tailed unpaired $t$ test. A $p$ value $<0.05$ was considered statistically significant. The asterisks in the figures indicate as follows: $* p<0.05, * * p<0.01$, *** $p<0.001 ; g$ indicates Hedges' $g$. For the examination of activity correlation in the blind experiments, the required sample size $(N)$ was calculated by R3.6.3 using power.t.test function with the following arguments: sig.level $=0.05$, power $=0.8, \delta=1$, and $\mathrm{SD}=1(\delta=1, \mathrm{SD}=1$ were used to set the effect size as 1; Ihaka and Gentleman, 1996).

\section{Results}

\section{Sparse KO of GluN1 in L4 neurons does not affect} thalamocortical terminal clustering

Cortex-specific GluN1KO leads to altered thalamocortical terminal patterning (Iwasato et al., 2000). In the current study, we aimed to examine activity correlation subsequent to GluN1KO in a subset of barrel neurons without affecting thalamocortical terminal patterns. To achieve this, we used the Supernova vector system, which enables single-cell labeling and labeled cell-specific gene KO (Mizuno et al., 2014; Luo et al., 2016). To analyze thalamocortical axon clustering in vivo, we used TCA-RFP Tg mice, in which thalamocortical axons were labeled with RFP (Mizuno et al., 2018a). We electroporated the Supernova-GCaMP6s vector set into E14 embryos obtained from an intercross between TCARFP; Grin1floxed/+ male and Grin1floxed/floxed female mice. We considered GCaMP-labeled L4 neurons in TCA-RFP; Grin1floxed/+ pups and TCA-RFP; Grin1floxed/floxed pups as GluN1 heterozygous control L4 neurons and GluN1KO L4 neurons, respectively (Fig. 1A). To analyze the dendritic morphology of L4 neurons following in vivo two-photon calcium imaging, a 
A

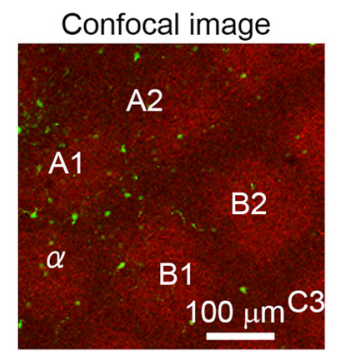

D

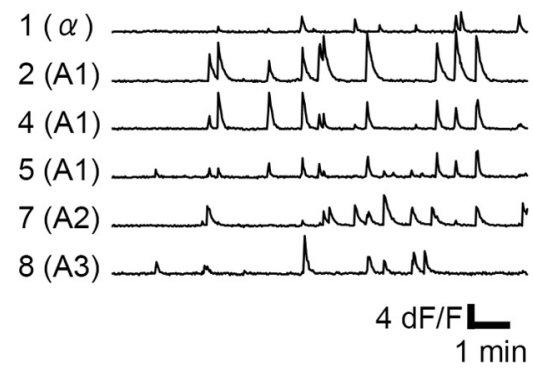

$\mathbf{F}$

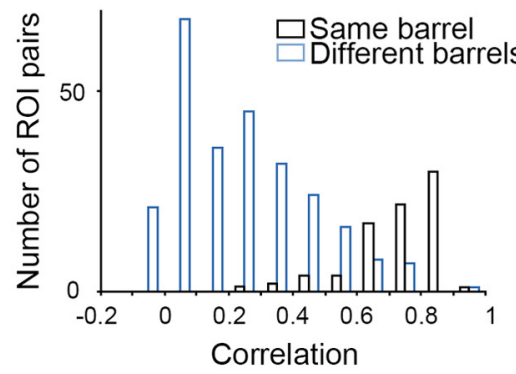

B

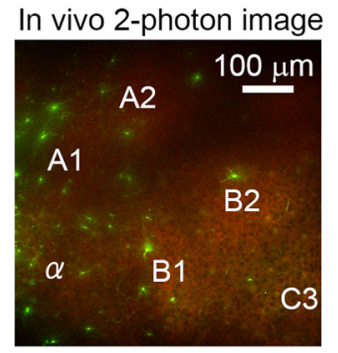

C

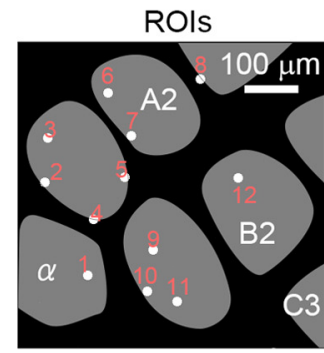

E

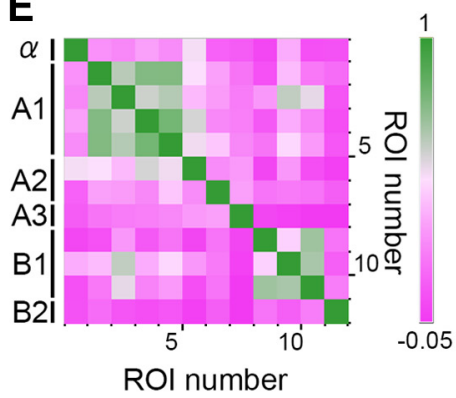

G
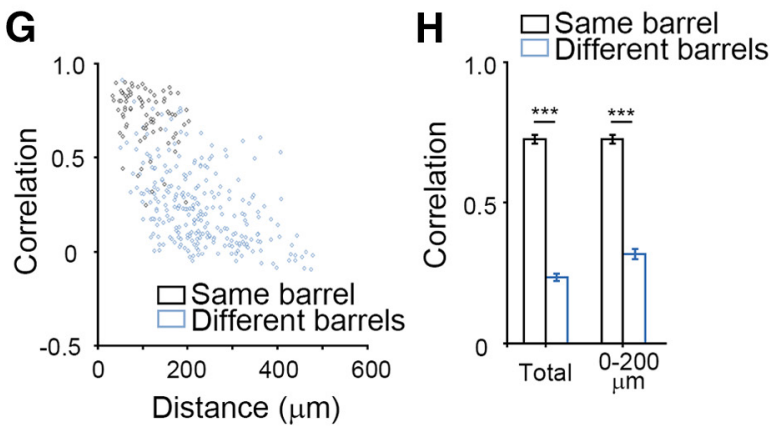

Figure 2. Patchwork-type spontaneous activity in control L4 neurons. $\boldsymbol{A}$, Confocal image of a representative tangential section from a Supernova-GCaMP6s-transfected TCA-RFP; Grin1floxed/ + mouse, taken after in vivo imaging at P6. $\boldsymbol{B}$, Time-lapse in vivo calcium imaging was performed in the same region as in $\boldsymbol{A}$. $\boldsymbol{C}$, ROls are located on the cell bodies of neurons imaged in $\boldsymbol{B}$. $\boldsymbol{D}$, Changes in fluorescence signals in the ROls indicated in $\boldsymbol{C}$. $\boldsymbol{E}$, Correlation matrix calculated from the fluorescence signals of all ROI pairs measured in $\boldsymbol{C}$. $\boldsymbol{F}$, Correlation values of ROl pairs of GluN1 heterozygous L4 neurons within the same barrel were higher than those in different barrels $(p<0.001)$. $\mathbf{G}$, Distribution of correlation values for cell pairs from the same barrel and different barrels with respect to distance. $\boldsymbol{H}$, Comparison of correlation values between R0I pairs from the same barrel and those from different barrels (total: $p<0.001 ; 0-200 \mu \mathrm{m}$ : $p<0.001$ ). Error bars indicate SE.

CAG-loxP-STOP-loxP-LacZ-ires-tTA-WPRE vector was mixed with the Supernova-GCaMP6s vector set for electroporation (Fig. 1B).

Comparisons of the total area of RFP-labeled thalamocortical axon terminals in the $\mathrm{C} 1$ barrel showed similarities between the sparse cell GluN1KO and control conditions (control, seven mice; GluN1KO, four mice; $p=0.625, t=0.506, g=0.317$; Fig. $1 C, D)$. The length (i.e., arc direction) and width (i.e., row direction) of the $\mathrm{C} 1$ barrels of the controls and GluN1KOs were found to be similar as well (length, $p=0.572, t=0.587, g=0.368$; width, $p=0.205, t=1.366, g=0.856$ ). These results suggest that GluN1KO in a small population of L4 neurons had little impact on thalamocortical axon cluster formation in the barrel cortex.

\section{Existence of $\mathrm{L} 4$ patchwork activity in GluN1 KO neurons}

We conducted in vivo two-photon calcium imaging of control and GluN1KO L4 neurons at postnatal day (P)6 (Figs. 2, 3). Histologic analyses following in vivo imaging revealed the imaged area (Figs. 2A, 3A). To quantitatively characterize the spontaneous activity of individual L4 neurons, we defined ROIs on each cell, and examined temporal changes in GCaMP6s fluorescence (Fig. 2B-D). Sparse cell labeling by the Supernova system allowed us to extract calcium transients without neuropil signal correction (Mizuno et al., 2018a). There were no significant differences between the frequency of calcium events in the control and GluN1KO neurons (control: $1.01 \pm 0.11 \mathrm{event} / \mathrm{min}$, $n=34$; GluN1KO: $0.93 \pm 0.09$ event $/ \mathrm{min} n=17 ; p=0.620$, $t=0.499, g=0.148)$. This is consistent with an earlier study showing that sparse GluN1KO in L4 neurons did not change the electrophysiological properties of those neurons (Mizuno et al., 2014).

We characterized the correlation of spontaneous activity of GluN1KO neuron pairs by calculating Pearson's correlation coefficient between fluorescence signals for each pair of ROIs placed on L4 neurons (Figs. $2 E-H, 3 E-H$ ). A color-coded correlation matrix indicated that the boundary of high-synchrony areas corresponded to the boundaries of the barrel compartments (Figs. $2 E, 3 E$, green areas). The correlation value distributions of ROI pairs from the same barrel and those from different barrels were distinguished (control, same barrel: $0.726 \pm 0.015$, 81 pairs from nine mice; different barrels: $0.233 \pm 0.012,256$ pairs from nine mice; $p<0.001, t=25.017, g=2.670$; GluN1KO, same barrel: $0.637 \pm 0.030,29$ pairs from five mice; different barrels: $0.167 \pm 0.008,143$ pairs from five mice; $p<0.001$, $t=14.861, g=4.251$; Figs. $2 F, H, 3 F, H)$. We also assessed the correlation values of cell pairs with respect to cell-cell distance. 


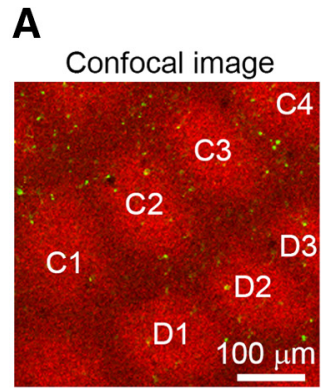

B

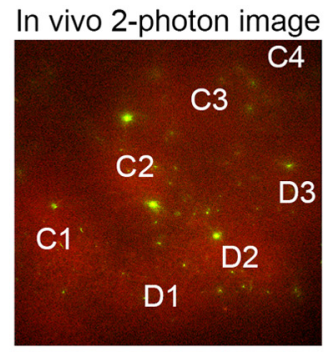

C

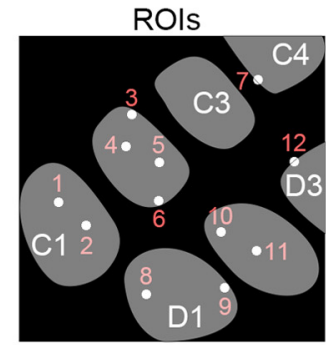

D
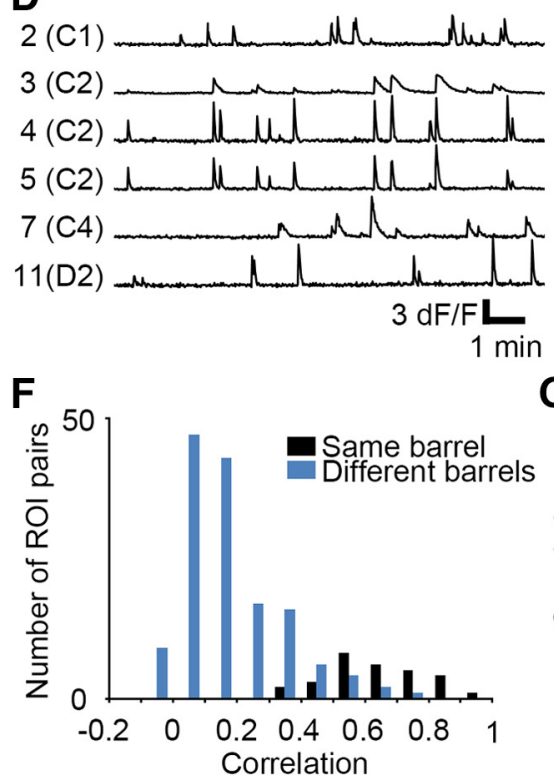

E 1

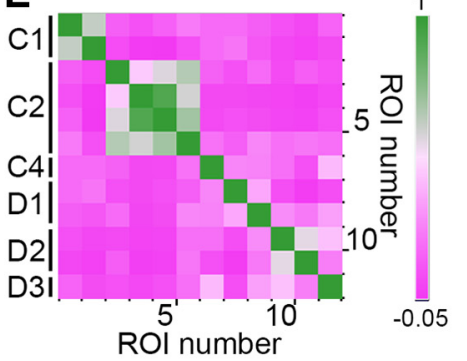

G

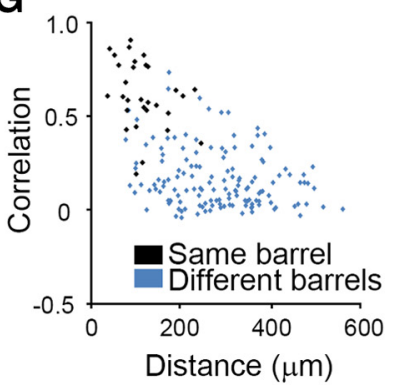

Figure 3. Patchwork-type spontaneous activity in GluN1KO L4 neurons. $\boldsymbol{A}$, Confocal image of a representative tangential section from a Supernova GCaMP6s-transfected TCA-RFP; Grin1floxed/floxed mouse at P6. $\boldsymbol{B}$, In vivo calcium imaging was performed at the same region as in $\boldsymbol{A}$. $\boldsymbol{C}$, ROls are indicated on the cell bodies of neurons imaged in $\boldsymbol{B}$. $\boldsymbol{D}$, Changes in fluorescence signals in the ROls indicated in $\boldsymbol{C}$. $\boldsymbol{E}$, Correlation matrix calculated from the fluorescence signals of all ROI pairs in $\boldsymbol{C}$. $\boldsymbol{F}$, Correlation values of R0I pairs from the GluN1K0 neurons within the same barrel were higher than in different barrels $(p<0.001)$. $\mathbf{G}$, Distribution of correlation values for cell pairs from the same barrel and from different barrels with respect to distance. $\boldsymbol{H}$, Comparison of correlation values between R0I pairs from the same barrel and those from different barrels in GluN1K0 cell pairs (total: $p<0.001 ; 0-200 \mu$ m: $p<0.001$ ). Error bars indicate SE.

Correlation values demonstrated an inverse relationship with distance for both intrabarrel and interbarrel pairs, indicating that synchronized activity was also dependent on the distance between cell pairs (Figs. 2G, 3G). To avoid effects of distance, we compared the correlation values of cell pairs located within $200 \mu \mathrm{m}$ (approximate barrel width) between intrabarrel and interbarrel groups. We found that correlation values in cell pairs from the same barrel were higher than those from different barrels (control, same barrel: $0.727 \pm 0.016,80$ pairs; different barrels: $0.316 \pm 0.019,106$ pairs; $p<0.001, t=16.717, g=2.365$; GluN1KO, same barrel: $0.647 \pm 0.030,27$ pairs; different barrels: $0.203 \pm 0.028,42$ pairs; $p<0.001, t=10.603, g=2.615$; Figs. $2 H$, $3 H)$. These findings indicate that GluN1KO cells display patchwork activity.

\section{GluN1KO neurons within a barrel display lower activity correlation}

Next, we compared the correlation value of ROI pairs from the same barrel between control cells and GluN1KO cells. The average correlation value was lower in GluN1KO neurons than in controls $(p=0.005, t=2.860, g=0.613$; Fig. $4 A, C)$, suggesting the NMDAR is involved in the enhancement of activity correlation within each barrel. We assessed the correlation values of cell pairs with respect to cell-cell distance (Fig. $4 B, C$ ), and found that the correlation values in cell pairs located within $200 \mu \mathrm{m}$ was reduced in GluN1KO neurons ( $p=0.014, t=2.496, g=0.555$; Fig. $4 C)$. As this distance was similar to barrel width and length, the correlation values of cell pairs might relate to cell position within each barrel (barrel center or barrel edge). We found that the reduction of correlation values in GluN1KO neurons was most evident when at least one cell in the pair was located at the edge of the barrel (control: $0.718 \pm 0.016,73$ pairs; GluN1KO: $0.629 \pm 0.033,23$ pairs; $p=0.012, t=2.577, g=0.616$; Fig. $4 D$ ). These results suggest that NMDARs are essential for the enhancement of activity correlation among L4 neurons, particularly at the edge of barrels.

\section{Lower activity correlation in GluN1KO neurons between barrels}

The control cell pairs in different barrels $<200 \mu \mathrm{m}$ apart demonstrated activity correlation, albeit at a low level $(\sim 0.5$; Fig. $2 F-H)$. We found that the activity correlation between neighboring barrels was also present in GluN1KO neuron pairs, but the level of correlation value was even lower in the GluN1KO neuron pairs than in control neuron pairs $(p<0.001, t=3.693, g=0.392$; Fig. $5 A, C)$. This suggests that NMDARs are involved in the 
A

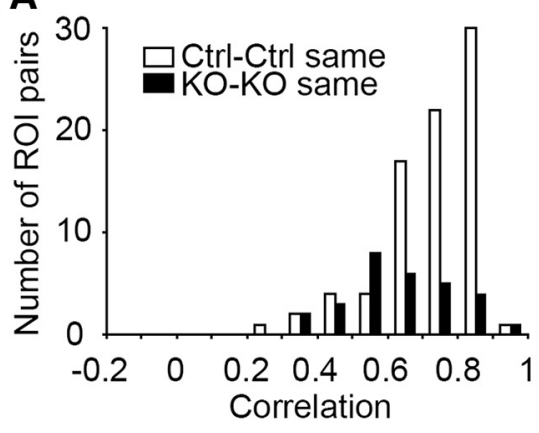

D
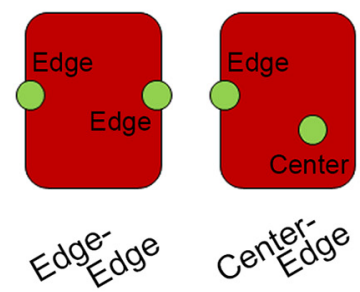

B

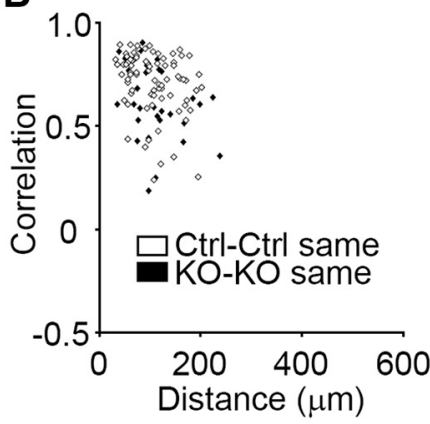

C

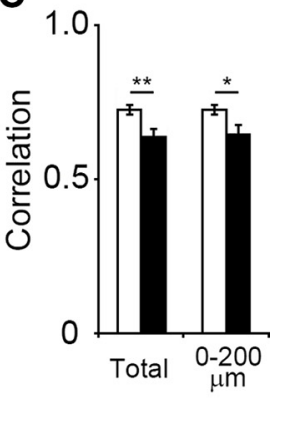

Figure 4. Intrabarrel activity correlation of $L 4$ neurons is reduced by GluN1 disruption. $\boldsymbol{A}$, Correlation value distributions of control cell pairs in the same barrel (Ctrl-Ctrl same) and GluN1KO cell pairs in the same barrel (KO-KO same). B, Distribution of correlation values for cell pairs from the same barrel with respect to cell-cell distance. C, Comparison of intrabarrel correlation values of Ctrl-Ctrl neuron pairs and those of KO-KO neuron pairs (total, $p=0.005 ; 0-200 \mu \mathrm{m}, p=0.014$ ). $\boldsymbol{D}$, Comparison of correlation values of neuron pairs with respect to their positions within a barrel. Error bars indicate SE.

A

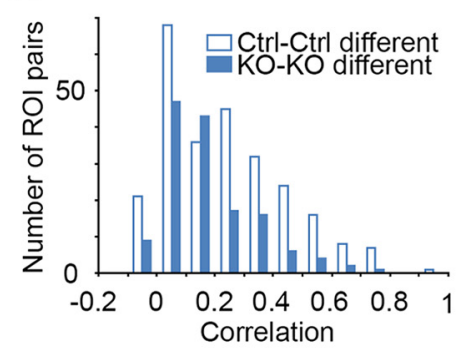

D

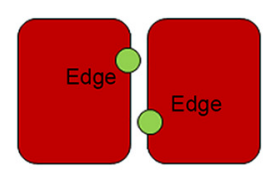

Edg Edge
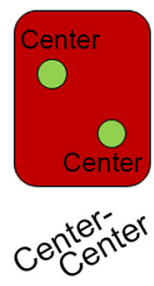

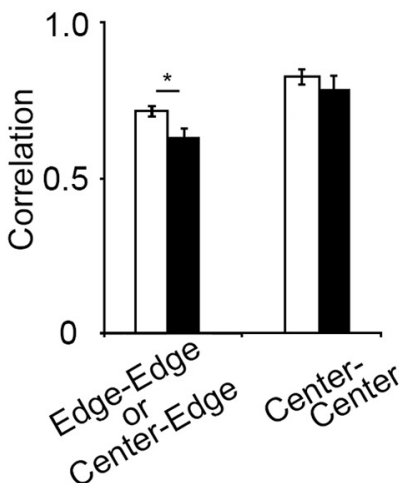

B

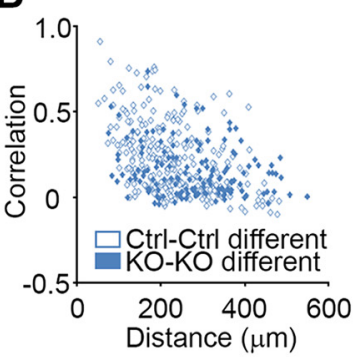

C
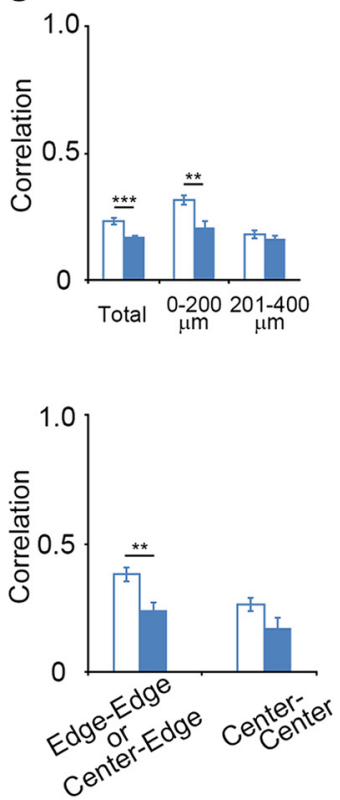

Figure 5. Interbarrel activity correlation is also reduced by GluN1 disruption. $\boldsymbol{A}$, Correlation value distributions of control cell pairs from different barrels (Ctrl-Ctrl different) and GluN1KO cell pairs from different barrels (KO-KO different). $\boldsymbol{B}$, Distribution of correlation values for cell pairs from different barrels with respect to cell-cell distance. $\boldsymbol{C}$, Comparison of interbarrel correlation values of control neuron pairs and those of GluR1K0 neuron pairs (total, $p<0.001 ; 0-200 \mu \mathrm{m}, p=0.002 ; 201-400 \mu \mathrm{m}, p=0.348$ ). $\boldsymbol{D}$, Comparison of correlation values between R0I pairs with respect to cell position within the barrel. Error bars indicate SE.

enhancement of activity correlation between neighboring barrels. We assessed the correlation values of cell pairs with respect to cell-cell distance in control and GluN1KO cells and found that the correlation values within $200 \mu \mathrm{m}$ were reduced in GluN1KO neuron pairs ( $p=0.002, t=3.226, g=0.588$; Fig. $5 B, C)$. We also examined the relationship between the correlation values and cell position, and found reduced correlation values in GluN1KO cell pairs in which at least one cell was on the edge of the barrel 
A

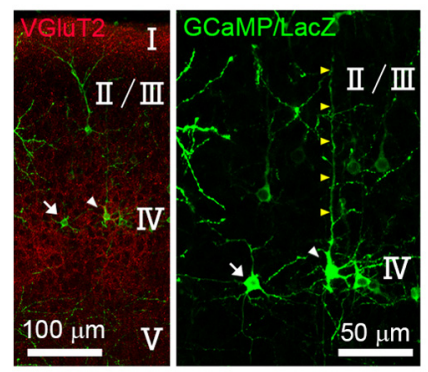

C

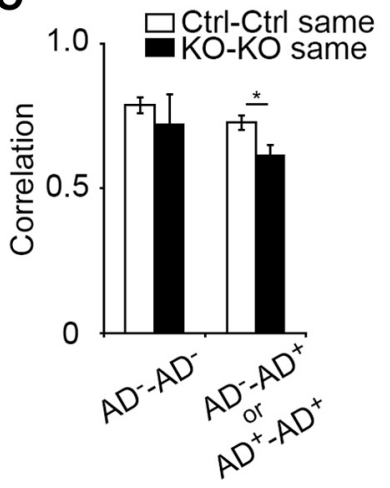

B
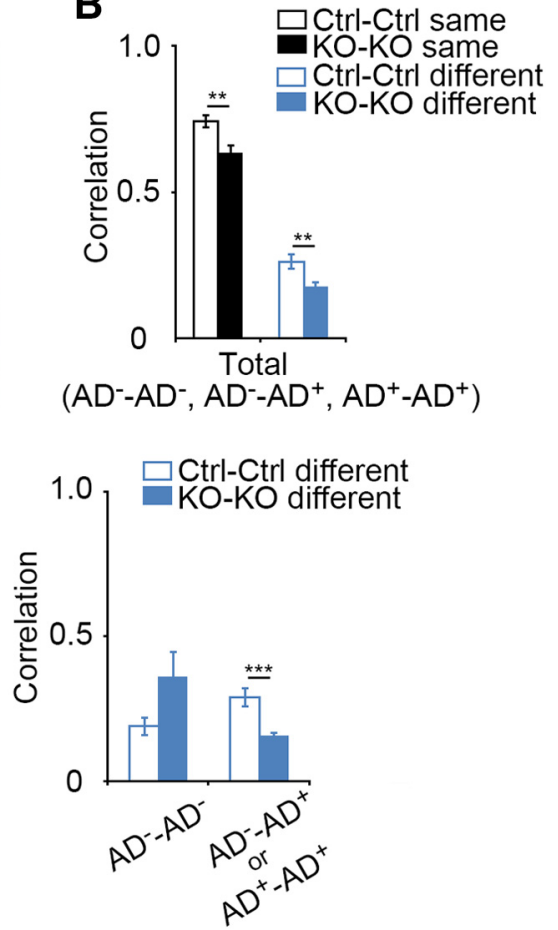

Figure 6. Lower activity correlation in apical dendrite-possessing GluN1KO neurons. $\boldsymbol{A}$, Representative images of an $L 4$ neuron lacking an apical dendrite $\left(A D^{-}\right.$: a mature $S S$ neuron), and an $L 4$ neuron with an apical dendrite $\left(\mathrm{AD}^{+}\right.$: an SP neuron or immature SS neuron) in the coronal section at P6. Arrows: an $A D^{-}$ neuron; white arrowheads: an $A D^{+}$neuron; yellow arrowheads: an apical dendrite. The right panel is higher magnification image of the left panel. $\boldsymbol{B}$, Comparisons of correlation values between control neuron pairs and GluN1K0 neuron pairs (control same vs GluN1K0 same, $p=0.003$; control different vs GluN1KO different, $p=0.006$ ). In these analyses, cells whose cell-types were not clear were excluded. $\boldsymbol{C}$, Relationship between activity correlation and apical dendrite morphology. The activity correlation of cell pairs that contain at least one $\mathrm{AD}^{+}$cell was lower in GluN1K0 than in control (same barrel, $p=0.012$; different barrels, $p<0.001$ ). Error bars indicate SE.

(control: $0.364 \pm 0.027,54$ pairs; GluN1KO: $0.238 \pm 0.030,20$ pairs; $p=0.006, t=2.844, g=0.744$; Fig. $5 D$ ). These results suggest that NMDARs are necessary for the enhancement of correlated L4 neuron activity at the edges of neighboring barrels.

\section{GluN1KO reduces correlation of neuronal activity in neurons with apical dendrites}

We then determined whether GluN1KO-dependent reduction of the correlation of L4 neuronal activity was associated with the neuronal morphology. LacZ immunostaining was used to discriminate between the presence and absence of apical dendrite in GCaMP6s-expressing neurons (Fig. 6A). L4 neurons without apical dendrites (spiny stellate neurons) were defined as $\mathrm{AD}^{-}$cells, and those with apical dendrites (star pyramid neurons or spiny stellate neurons in an immature state) were defined as $\mathrm{AD}^{+}$cells. We confirmed that activity correlation of cell pairs, in which their apical dendrite morphology was identified, was lower in GluN1KO neurons compared with control neurons (same barrel, control: $0.744 \pm 0.020,38$ pairs, GluN1KO: $0.634 \pm 0.032,21$ pairs, $p=0.003, t=3.136, g=0.935$; different barrels, control: $0.263 \pm 0.026$, 69 pairs, GluN1KO: $0.173 \pm 0.016,105$ pairs, $p=0.003, t=2.808, g=0.464$; Fig. $6 B$ ). The correlation of activity in cell pairs that contained at least one $\mathrm{AD}^{+}$cell $\left(\mathrm{AD}^{-}-\mathrm{AD}^{+}\right.$ and $\mathrm{AD}^{+}-\mathrm{AD}^{+}$) was lower in GluN1KO than in control neurons (same barrel, control: $0.727 \pm 0.025,27$ pairs, GluN1KO: $0.619 \pm$ $0.034,18$ pairs, $p=0.012, t=2635, g=0.802$; different barrels,

control: $0.289 \pm 0.033,51$ pairs, GluN1KO: $0.157 \pm$ 0.014, 97 pairs, $p<0.001, t=3.712, g=0.742$; Fig. $6 C, D)$. These findings indicate that GluN1KO reduces the correlated activity in $\mathrm{AD}^{+}$neurons.

\section{Normal level of activity correlation in control- GluN1KO neuron pairs}

The above data suggested a reduction in activity correlation in GluN1KO neuron pairs. To further unravel the role of NMDAR in correlation of activity, we determined the level of activity correlation in normal neuron and GluN1KO neuron pairs (control-KO pairs). To discriminate GluN1KO neurons and neighboring control neurons within the same cortex, we transfected a vector set containing Cre-based Supernova-CyRFP (TRE-Cre and CAG-loxP-STOP-loxP-CyRFP-ires-tTA-WPRE) into Grinlfloxed/floxed mice together with the CAG-Flpe and CAG-FRT-STOP-FRT-GCaMP6s vector set. In this condition, CyRFP/GCaMP6s double-positive cells represented GluN1KO neurons, while GCaMP6s single-positive cells represented control neurons (Fig. $7 A-E)$. Quantitative analysis showed that activity correlation was not altered in control-GluN1KO cell pairs comparing with control-control cell pairs (same barrel control-control pairs: $0.738 \pm 0.050$, six pairs from three mice; same barrel control-KO pairs: $0.743 \pm 0.030$, 10 pairs from three mice; $p=0.913, t=0.111, g=0.057$; different barrels, control-control pairs: $0.309 \pm 0.032,13$ pairs from three mice; different barrels, control-KO pairs: $0.301 \pm 0.040,14$ pairs from three mice; $p=0.873$, $t=0.161, g=0.062$; Fig. $7 F)$. These findings suggest that the loss of NMDAR in one cell in a pair is not sufficient to reduce the correlation of neuronal activity.

\section{Discussion}

The KO of GluN1 in a small population of L4 neurons had little impact on thalamocortical axon cluster formation (Fig. 1). This allowed us to examine the role of NMDARs in the correlation of thalamocortical axon-derived activity in L4 neurons (Figs. 2-6). NMDARs were determined to be involved in the enhancement of spontaneous activity correlation within cortical barrels (Fig. 4) and between neighboring barrels (Fig. 5). GluN1KO reduces activity correlation chiefly in cell pairs possessing apical dendrites (Fig. 6). Our findings suggest that NMDARs are necessary for spontaneous activity correlation in the development of cortical neurons in L4.

\section{NMDARs in L4 neuron are involved in correlation of neuronal activity}

Patchwork activity, the correlated spontaneous activity between cell pairs within a single barrel, was maintained in GluN1KO L4 neurons. This is consistent with our earlier finding that patchwork activity during the first postnatal week is mediated by the thalamus (Mizuno et al., 2018a; Nakazawa et al., 2020). However, although this patchwork pattern was evident, the activity correlation level of L4 neurons within barrels was reduced in GluN1KO-GluN1KO neuron pairs compared with control-control neuron pairs, indicating that activity correlation is enhanced by postsynaptic NMDARs at the thalamocortical synapse.

We found a low-level correlation of activity between neighboring barrels in control cell pairs (Fig. $2 F-H$ ). This is likely because several dendritic branches can be located outside the 
A

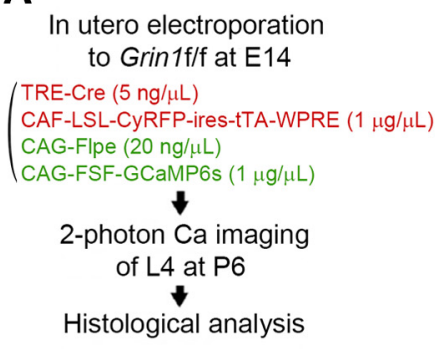

E

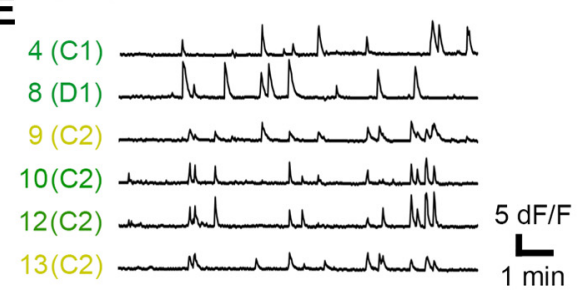

B
Confocal image

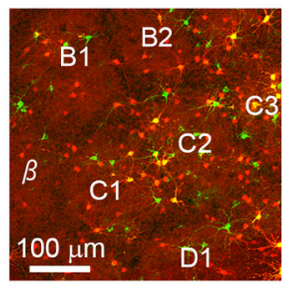

C

In vivo 2-photon image
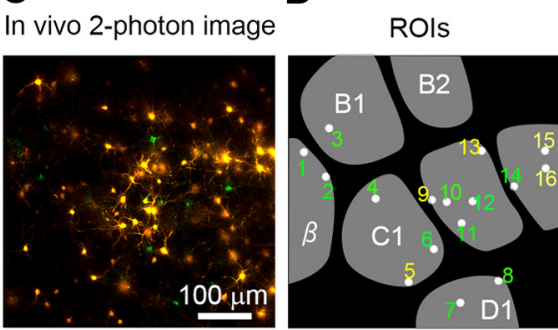

F 1.0

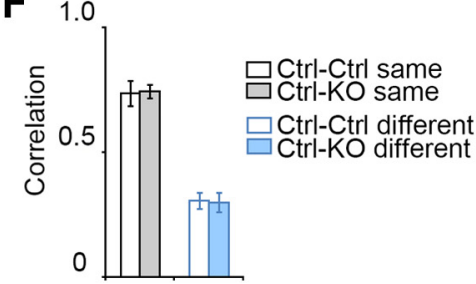

Figure 7. Activity correlation is not altered in control-GluN1KO cell pairs. $A$, An approach that enables activity correlation analysis of control-GluN1KO neuron pairs. Cre-based SupernovaCyRFP (TRE-Cre and CAG-loxP-STOP-loxP-CyRFP-ires-TTA-WPRE) vectors and combination of CAG-Flpe and CAG-FRT-STOP-FRT-GCaMP6s vectors were transfected together to Grinffloxed/floxed mice at E14. In this approach, CyRFP/GCaMP6s double-positive cells represent GluN1KO neurons, and GCaMP6s single-positive cells are control neurons. For details, see also Mizuno et al. (2014) and Luo et al. (2016). B, Confocal image of a tangential brain section from an electroporated mouse at P6. To visualize the barrel arrangement, vGluT2 immunostaining was performed (red signals with lower fluorescence). $\boldsymbol{C}$, In vivo calcium imaging performed at the same region as in $\boldsymbol{B}$. Note that distribution of labeled neurons is similar as in $\boldsymbol{B}$. $\boldsymbol{D}$, ROls are located on the cell bodies of GCaMP-positive neurons imaged in C. ROls numbered in yellow are CyRFP/GCaMP6s double-positive cells and in green are GCaMP6s single-positive cells. The barrel arrangement obtained by vGluT2 immunostaining in $\boldsymbol{B}$ is merged in gray. $\boldsymbol{E}$, Changes in fluorescence signals measured from the ROls indicated in $\boldsymbol{D}$. $\boldsymbol{F}$, Correlation values obtained from control-GluN1K0 (Ctrl-K0) cell pairs are compared with control-control (Ctrl-Ctrl) cell pairs (same barrel, $p=0.913$; different barrels, $p=0.873$ ). Error bars indicate SE.

barrel during normal development (Mizuno et al., 2014), and the thalamocortical inputs to these outward dendritic branches may increase the correlation between the neighboring barrels. This low-level correlation between neighboring barrels was even lower in GluN1KO cell pairs, despite more dendrites being located in neighboring barrels in GluN1KO cells than in control cells (Mizuno et al., 2014). If more dendrites are located on neighboring barrels, and these dendrites contribute to activity correlation, the correlation level would be expected to be higher (Model 1, correlation-detecting dendrites in GluN1KO; Fig. 8A). However, this was found not to be the case in GluN1KO cell pairs, suggesting that dendrites without NMDARs cannot detect or contribute to correlation of neuronal activity (Model 2, non-correlationdetecting dendrites in GluN1KO; Fig. $8 B$ ). This is supported by the fact that NMDARs are also involved in activity correlation enhancement within barrels (Fig. 4). Thus, NMDARs in L4 neurons may function as "activity correlation detectors" during thalamocortical circuit maturation (see also Fig. 8 legend).

The reduction of activity correlation was not detected in control-GluN1KO neuron pairs (Fig. 7). This may indicate that NMDAR-dependent detection of the correlated inputs from thalamocortical axons has a cumulative effect. High activity correlation in a control-control cell pair could be because of high correlation of both control L4 neurons with thalamocortical axons (Mizuno et al., 2018a). It is likely that activity correlation in KO-KO cell pairs is significantly low because the correlation with thalamocortical axons is low in both $\mathrm{KO}$ neurons. The high correlation between control L4 neurons and thalamocortical axons may make the presumable activity-correlation reduction in control-KO cell pairs undetectable, although the activity correlation between $\mathrm{KO}$ neurons and thalamocortical axons is reduced.

\section{Roles of NMDAR-dependent correlation of activity in L4 circuit maturation}

The correlated activity in cell pairs comprising $\mathrm{AD}^{+}$neurons was reduced in GluN1KO neurons (Fig. 6C). Spiny stellate neurons, the major type of the excitatory neurons in the barrel cortex L4, have an apical dendrite at birth that is lost during development (Callaway and Borrell, 2011; Nakazawa et al., 2018), suggesting that $\mathrm{AD}^{+}$neurons should contain immature spiny stellate neurons. Interestingly, we noticed that the ratio of $\mathrm{AD}^{+}$ neurons tended to be lower in GluN1KO neurons $(26.7 \%, 8$ cells $/ 30$ cells) than in controls $(48.6 \%, 18$ cells/37 cells), indicating that retraction of the apical dendrite in spiny stellate neurons might be disturbed or delayed by GluN1KO. This morphologic defect in GluN1KO L4 neurons is consistent with earlier reports that NMDARs are necessary for another aspect of dendrite maturation, orientation bias (Espinosa et al., 2009; Mizuno et al., 2014). These results indicate that NMDAR-mediated correlation of neuronal activity may affect maturation of spiny stellate neurons. Other considerable possibilities are that morphologic maturation may promote correlation of activity or that morphologic maturation and the activity correlation enhancement are mutually affected. To analyze the causality between dendrite morphology and activity correlation, additional experiments is needed. Induction of correlated activity in GluN1KO L4 neurons using optogenetic tools (Boyden et al., 2005) may facilitate dendritic maturation.

In this study, we examined the morphology of L4 neuron dendrites in histologic sections acquired following in vivo calcium imaging. To understand the role of correlated activity in the L4 circuit maturation, simultaneous in vivo imaging of dendrite dynamics and calcium activity changes is favored. We are currently preparing experimental strategies to analyze the roles of NMDAR-dependent correlated activity in the dynamic formation of neuronal circuits in living animals.

\section{Molecular mechanisms that enhance correlation of neuronal activity}

We found that a certain level of activity correlation was maintained in GluN1KO L4 neuron pairs. This might 
A

Within barrel

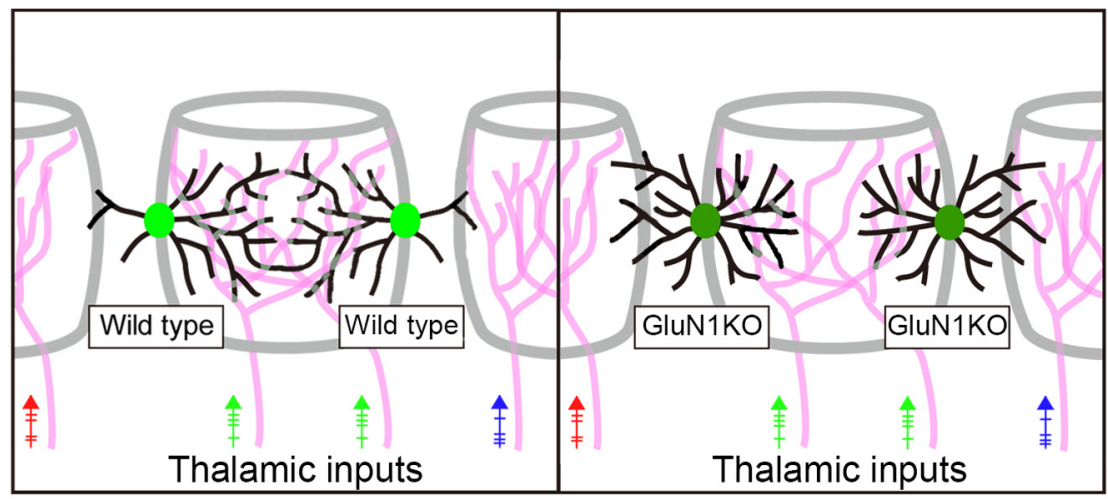

Between barrels

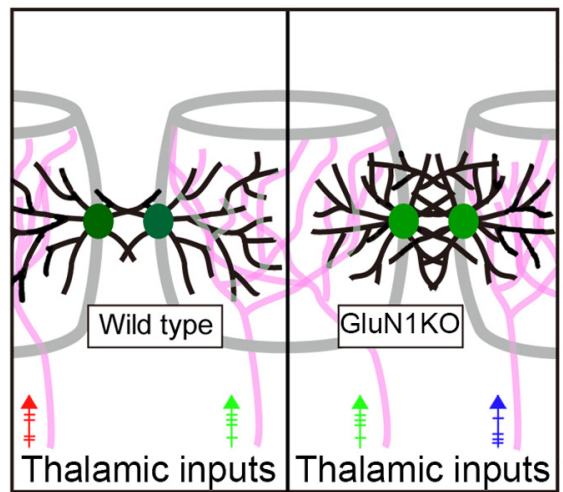

B

Within barrel

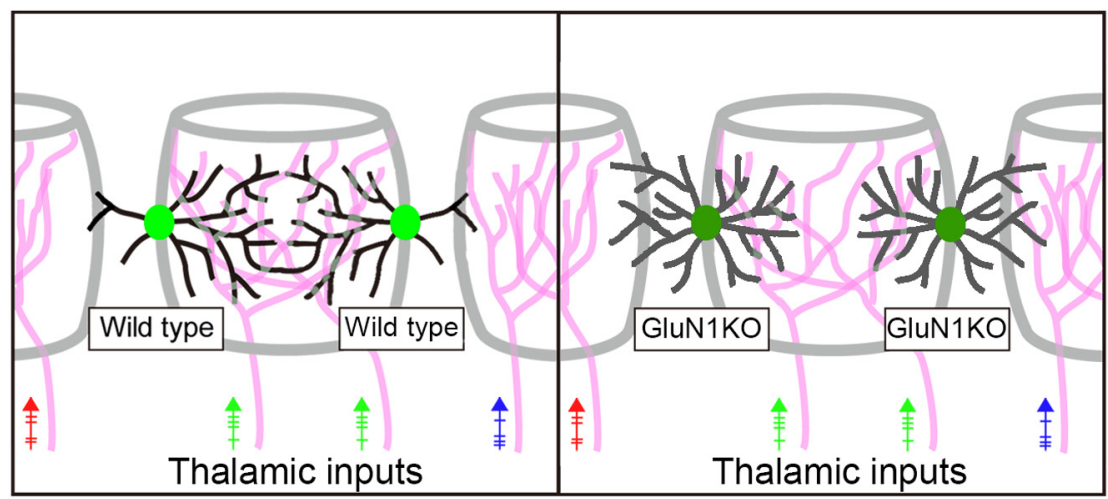

Between barrels

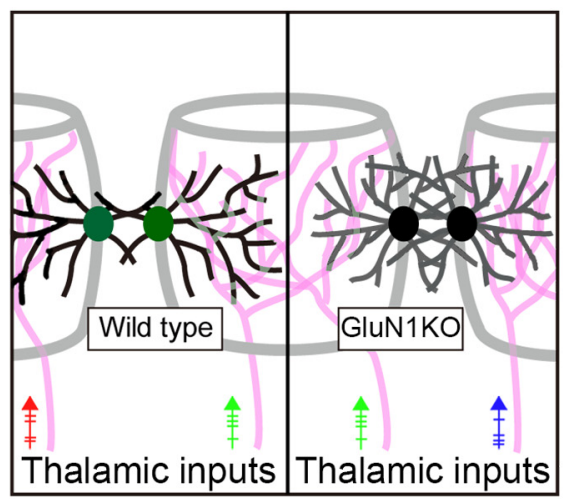

\section{Activity correlation level High 0000 Low}

Figure 8. Models of NMDA receptor-dependent enhancement of correlated neuronal activity in the neonatal barrel cortex. A, Model 1: correlation-detecting dendrites in GluN1K0. In this model, NMDAR-independent Hebbian-type plasticity occurs in the dendrites of GluN1K0 neurons. Since NMDAR-independent plasticity occurs on "correlation-detecting" dendrites located in neighboring barrels, activity correlation of GluN1KO neuron pairs within a barrel would be lower than that of wild-type neuron pairs (left, within barrel). In this model, activity correlation between adjacent barrels is expected to be higher in GluN1K0 neuron pairs than that in wild-type neuron pairs (right, between barrels), since correlation-detecting dendrites heavily overlap in GluN1KO neurons. B, Model 2: non-correlation-detecting dendrites in GluN1KO neurons. In this model, NMDAR-independent Hebbian-type plasticity does not occur at the dendrites of GluN1KO neurons. As in Model 1, activity correlation of GluN1K0 neuron pairs within a barrel would be lower than that of wild-type neuron pairs (left, within barrel), since there is no Hebbian-type plasticity in GluN1KO neuron dendrites. However, unlike Model 1, the activity correlation of GluN1KO neuron pairs between the adjacent barrels would also be lower than that of wild-type neuron pairs in this model (right, between barrels), since the overlapping "non-correlation-detecting" dendrites in GluN1KO neurons do not drive Hebbian-type plasticity. The results of this study suggest that Model 2 is more likely.

suggest the involvement of other molecules in activity correlation enhancement. Previous studies have reported that various molecules were involved in the formation of L4 neuronal circuits (Cases et al., 1996; Welker et al., 1996; Erzurumlu and Kind, 2001; Persico et al., 2001; Hannan et al., 2001; Rebsam et al., 2002; Barnett et al., 2006; InceDunn et al., 2006; Inan and Crair, 2007; Iwasato et al., 2008; Ballester-Rosado et al., 2010; Wu et al., 2011; NarbouxNême et al., 2012), and these molecules might be involved in activity correlation enhancement. In vivo calcium imaging of L4 neurons in which these barrel-related genes were repressed by the Supernova system may provide insights into the molecular mechanisms behind the enhancement of correlated neuronal activity.

The downstream signaling events of NMDAR-mediated detection of correlated activity are also unknown. Dendritic orientation is disturbed in GluN1KO L4 neurons, and a similar phenotype has been described by in utero electroporationmediated knock-down of BTBD3 in L4 excitatory neurons (Matsui et al., 2013) and adenylyl cyclase $1 \mathrm{KO}$ in cortical excitatory neurons (Iwasato et al., 2008). Detection of correlated inputs from thalamocortical axons by NMDARs may affect these intracellular signaling molecules and drive dendritic patterning or morphology. 


\section{References}

Ackman JB, Crair MC (2014) Role of emergent neural activity in visual map development. Curr Opin Neurobiol 24:166-175.

Ackman JB, Burbridge TJ, Crair MC (2012) Retinal waves coordinate patterned activity throughout the developing visual system. Nature 490:219225.

Akhmetshina D, Nasretdinov A, Zakharov A, Valeeva G, Khazipov R (2016) The nature of the sensory input to the neonatal rat barrel cortex. J Neurosci 36:9922-9932.

Antón-Bolaños N, Sempere-Ferràndez A, Guillamón-Vivancos T, Martini FJ, Pérez-Saiz L, Gezelius H, Filipchuk A, Valdeolmillos M, López-Bendito G (2019) Prenatal activity from thalamic neurons governs the emergence of functional cortical maps in mice. Science 364:987-990.

Arakawa H, Suzuki A, Zhao S, Tsytsarev V, Lo FS, Hayashi Y, Itohara S, Iwasato T, Erzurumlu RS (2014) Thalamic NMDA receptor function is necessary for patterning of the thalamocortical somatosensory map and for sensorimotor behaviors. J Neurosci 34:12001-12014.

Ballester-Rosado CJ, Albright MJ, Wu CS, Liao CC, Zhu J, Xu J, Lee LJ, Lu HC (2010) mGluR5 in cortical excitatory neurons exerts both cell-autonomous and -nonautonomous influences on cortical somatosensory circuit formation. J Neurosci 30:16896-16909.

Barnett MW, Watson RF, Vitalis T, Porter K, Komiyama NH, Stoney PN, Gillingwater TH, Grant SG, Kind PC (2006) Synaptic Ras GTPase activating protein regulates pattern formation in the trigeminal system of mice. J Neurosci 26:1355-1365.

Boyden ES, Zhang F, Bamberg E, Nagel G, Deisseroth K (2005) Millisecondtimescale, genetically targeted optical control of neural activity. Nat Neurosci 8:1263-1268.

Callaway EM, Borrell V (2011) Developmental sculpting of dendritic morphology of layer 4 neurons in visual cortex: influence of retinal input. J Neurosci 31:7456-7470.

Cases O, Vitalis T, Seif I, De Maeyer E, Sotelo C, Gaspar P (1996) Lack of barrels in the somatosensory cortex of monoamine oxidase A-deficient mice: role of a serotonin excess during the critical period. Neuron 16:297-307.

Cang J, Feldheim DA (2013) Developmental mechanisms of topographic map formation and alignment. Annu Rev Neurosci 36:51-77.

Cline HT, Constantine-Paton M (1990) NMDA receptor agonist and antagonists alter retinal ganglion cell arbor structure in the developing frog retinotectal projection. J Neurosci 10:1197-1216.

Crair MC, Malenka RC (1995) A critical period for long-term potentiation at thalamocortical synapses. Nature 375:325-328.

Datwani A, Iwasato T, Itohara S, Erzurumlu RS (2002) NMDA receptor-dependent pattern transfer from afferents to postsynaptic cells and dendritic differentiation in the barrel cortex. Mol Cell Neurosci 21:477-492.

Erzurumlu RS, Jhaveri S (1990) Thalamic axons confer a blueprint of the sensory periphery onto the developing rat somatosensory cortex. Brain Res Dev Brain Res 56:229-234.

Erzurumlu RS, Kind PC (2001) Neural activity: sculptor of 'barrels' in the neocortex. Trends Neurosci 24:589-595.

Espinosa JS, Wheeler DG, Tsien RW, Luo L (2009) Uncoupling dendrite growth and patterning: single-cell knockout analysis of NMDA receptor 2B. Neuron 62:205-217.

Fox K (2008) Barrel cortex. Cambridge: Cambridge University Press.

Fukuchi-Shimogori T, Grove EA (2001) Neocortex patterning by the secreted signaling molecule FGF8. Science 294:1071-1074.

Golshani P, Gonçalves JT, Khoshkhoo S, Mostany R, Smirnakis S, PorteraCailliau C (2009) Internally mediated developmental desynchronization of neocortical network activity. J Neurosci 29:10890-10899.

Hanganu IL, Ben-Ari Y, Khazipov R (2006) Retinal waves trigger spindle bursts in the neonatal rat visual cortex. J Neurosci 26:6728-6736.

Hannan AJ, Blakemore C, Katsnelson A, Vitalis T, Huber KM, Bear M, Roder J, Kim D, Shin HS, Kind PC (2001) PLC-beta1, activated via mGluRs, mediates activity-dependent differentiation in cerebral cortex. Nat Neurosci 4:282-288.

Holtmaat A, Bonhoeffer T, Chow DK, Chuckowree J, De Paola V, Hofer SB, Hübener M, Keck T, Knott G, Lee WC, Mostany R, Mrsic-Flogel TD, Nedivi E, Portera-Cailliau C, Svoboda K, Trachtenberg JT, Wilbrecht L (2009) Long-term, high-resolution imaging in the mouse neocortex through a chronic cranial window. Nat Protoc 4:1128-1144.

Huberman AD, Speer CM, Chapman B (2006) Spontaneous retinal activity mediates development of ocular dominance columns and binocular receptive fields in V1. Neuron 52:247-254.
Ihaka R, Gentleman R (1996) R: a language for data analysis and graphics. J Comput Graph Stat 5:299-314.

Ikezoe K, Tamura H, Kimura F, Fujita I (2012) Decorrelation of sensoryevoked neuronal responses in rat barrel cortex during postnatal development. Neurosci Res 73:312-320.

Inan M, Crair MC (2007) Development of cortical maps: perspectives from the barrel cortex. Neuroscientist 13:49-61.

Ince-Dunn G, Hall BJ, Hu SC, Ripley B, Huganir RL, Olson JM, Tapscott SJ, Ghosh A (2006) Regulation of thalamocortical patterning and synaptic maturation by NeuroD2. Neuron 49:683-695.

Iwasato T (2020) In vivo imaging of neural circuit formation in the neonatal mouse barrel cortex. Dev Growth Differ 62:476-486.

Iwasato T, Erzurumlu RS (2018) Development of tactile sensory circuits in the CNS. Curr Opin Neurobiol 53:66-75.

Iwasato T, Erzurumlu RS, Huerta PT, Chen DF, Sasaoka T, Ulupinar E, Tonegawa S (1997) NMDA receptor-dependent refinement of somatotopic maps. Neuron 19:1201-1210.

Iwasato T, Datwani A, Wolf AM, Nishiyama H, Taguchi Y, Tonegawa S, Knöpfel T, Erzurumlu RS, Itohara S (2000) Cortex-restricted disruption of NMDAR1 impairs neuronal patterns in the barrel cortex. Nature 406:726-731.

Iwasato T, Inan M, Kanki H, Erzurumlu RS, Itohara S, Crair MC (2008) Cortical adenylyl cyclase 1 is required for thalamocortical synapse maturation and aspects of layer IV barrel development. J Neurosci 28:59315943.

Kandler K, Clause A, Noh J (2009) Tonotopic reorganization of developing auditory brainstem circuits. Nat Neurosci 12:711-717.

Katz LC, Shatz CJ (1996) Synaptic activity and the construction of cortical circuits. Science 274:1133-1138.

Khazipov R, Sirota A, Leinekugel X, Holmes GL, Ben-Ari Y, Buzsáki G (2004) Early motor activity drives spindle bursts in the developing somatosensory cortex. Nature 432:758-761.

Kirkby LA, Sack GS, Firl A, Feller MB (2013) A role for correlated spontaneous activity in the assembly of neural circuits. Neuron 80:1129-1144.

Laviv T, Kim BB, Chu J, Lam AJ, Lin MZ, Yasuda R (2016) Simultaneous dual-color fluorescence lifetime imaging with novel red-shifted fluorescent proteins. Nat Methods 13:989-992.

Lee LJ, Iwasato T, Itohara S, Erzurumlu RS (2005) Exuberant thalamocortical axon arborization in cortex-specific NMDAR1 knockout mice. J Comp Neurol 485:280-292.

Li H, Fertuzinhos S, Mohns E, Hnasko TS, Verhage M, Edwards R, Sestan N, Crair MC (2013) Laminar and columnar development of barrel cortex relies on thalamocortical neurotransmission. Neuron 79:970-986.

Luo W, Mizuno H, Iwata R, Nakazawa S, Yasuda K, Itohara S, Iwasato T (2016) Supernova: a versatile vector system for single-cell labeling and gene function studies in vivo. Sci Rep 6:35747.

Matsui A, Tran M, Yoshida AC, Kikuchi SS, U M, Ogawa M, Shimogori T (2013) BTBD3 controls dendrite orientation toward active axons in mammalian neocortex. Science 342:1114-1118.

Meister M, Wong RO, Baylor DA, Shatz CJ (1991) Synchronous bursts of action potentials in ganglion cells of the developing mammalian retina. Science 252:939-943.

Mizuno H, Hirano T, Tagawa Y (2007) Evidence for activity-dependent cortical wiring: formation of interhemispheric connections in neonatal mouse visual cortex requires projection neuron activity. J Neurosci 27:6760-6770

Mizuno H, Hirano T, Tagawa Y (2010) Pre-synaptic and post-synaptic neuronal activity supports the axon development of callosal projection neurons during different post-natal periods in the mouse cerebral cortex. Eur J Neurosci 31:410-424.

Mizuno H, Luo W, Tarusawa E, Saito YM, Sato T, Yoshimura Y, Itohara S, Iwasato T (2014) NMDAR-regulated dynamics of layer 4 neuronal dendrites during thalamocortical reorganization in neonates. Neuron 82:365-379.

Mizuno H, Ikezoe K, Nakazawa S, Sato T, Kitamura K, Iwasato T (2018a) Patchwork-type spontaneous activity in neonatal barrel cortex layer 4 transmitted via thalamocortical projections. Cell Rep 22:123-135.

Mizuno H, Nakazawa S, Iwasato T (2018b) In vivo two-photon imaging of cortical neurons in neonatal mice. J Vis Exp 140:e58340.

Nakazawa S, Mizuno H, Iwasato T (2018) Differential dynamics of cortical neuron dendritic trees revealed by long-term in vivo imaging in neonates. Nat Commun 9:3106. 
Nakazawa S, Yoshimura Y, Takagi M, Mizuno H, Iwasato T (2020) Developmental phase transitions in spatial organization of spontaneous activity in postnatal barrel cortex layer 4. J Neurosci 40:7637-7650.

Narboux-Nême N, Evrard A, Ferezou I, Erzurumlu RS, Kaeser PS, Lainé J, Rossier J, Ropert N, Südhof TC, Gaspar P (2012) Neurotransmitter release at the thalamocortical synapse instructs barrel formation but not axon patterning in the somatosensory cortex. J Neurosci 32:6183-6196.

Persico AM, Mengual E, Moessner R, Hall SF, Revay RS, Sora I, Arellano J, DeFelipe J, Giménez-Amaya JM, Conciatori M, Marino R, Baldi A, Cabib S, Pascucci T, Uhl GR, Murphy DL, Lesch KP, Keller F (2001) Barrel pattern formation requires serotonin uptake by thalamocortical afferents, and not vesicular monoamine release. J Neurosci 21:6862-6873.

Petersen CC (2007) The functional organization of the barrel cortex. Neuron 56:339-355

Rao MS, Mizuno H (2020) Elucidating mechanisms of neuronal circuit formation in layer 4 of the somatosensory cortex via intravital imaging. Neurosci Res Advance online publication. Retrieved December 10, 2020. doi:10.1016/j.neures.2020.10.007.

Rebsam A, Seif I, Gaspar P (2002) Refinement of thalamocortical arbors and emergence of barrel domains in the primary somatosensory cortex: a study of normal and monoamine oxidase a knock-out mice. J Neurosci 22:8541-8552.

Saito T, Nakatsuji N (2001) Efficient gene transfer into the embryonic mouse brain using in vivo electroporation. Dev Biol 240:237-246.

Schindelin J, Arganda-Carreras I, Frise E, Kaynig V, Longair M, Pietzsch T, Preibisch S, Rueden C, Saalfeld S, Schmid B, Tinevez JY, White DJ, Hartenstein V, Eliceiri K, Tomancak P, Cardona A (2012) Fiji: an opensource platform for biological-image analysis. Nat Methods 9:676-682.

Sin WC, Haas K, Ruthazer ES, Cline HT (2002) Dendrite growth increased by visual activity requires NMDA receptor and Rho GTPases. Nature 419:475-480.

Stryker MP, Harris WA (1986) Binocular impulse blockade prevents the formation of ocular dominance columns in cat visual cortex. J Neurosci 6:2117-2133.

Sur M, Rubenstein JL (2005) Patterning and plasticity of the cerebral cortex. Science 310:805-810.

Tabata H, Nakajima K (2001) Efficient in utero gene transfer system to the developing mouse brain using electroporation: visualization of neuronal migration in the developing cortex. Neuroscience 103:865-872.
Thompson A, Gribizis A, Chen C, Crair MC (2017) Activity-dependent development of visual receptive fields. Curr Opin Neurobiol 42:136-143.

Tiriac A, Uitermarkt BD, Fanning AS, Sokoloff G, Blumberg MS (2012) Rapid whisker movements in sleeping newborn rats. Curr Biol 22:20752080.

Tritsch NX, Yi E, Gale JE, Glowatzki E, Bergles DE (2007) The origin of spontaneous activity in the developing auditory system. Nature 450:5055.

Tsutsumi S, Yamazaki M, Miyazaki T, Watanabe M, Sakimura K, Kano M, Kitamura K (2015) Structure-function relationships between aldolase C/ zebrin II expression and complex spike synchrony in the cerebellum. J Neurosci 35:843-852.

Welker E, Armstrong-James M, Bronchti G, Ourednik W, GheorghitaBaechler F, Dubois R, Guernsey DL, Van der Loos H, Neumann PE (1996) Altered sensory processing in the somatosensory cortex of the mouse mutant barrelless. Science 271:1864-1867.

Wong RO, Ghosh A (2002) Activity-dependent regulation of dendritic growth and patterning. Nat Rev Neurosci 3:803-812.

Wong RO, Chernjavsky A, Smith SJ, Shatz CJ (1995) Early functional neural networks in the developing retina. Nature 374:716-718.

Woolsey TA, Van der Loos H (1970) The structural organization of layer IV in the somatosensory region (SI) of mouse cerebral cortex. The description of a cortical field composed of discrete cytoarchitectonic units. Brain Res 17:205-242.

Woolsey TA, Wann JR (1976) Areal changes in mouse cortical barrels following vibrissal damage at different postnatal ages. J Comp Neurol 170:5366.

Woolsey TA, Dierker ML, Wann DF (1975) Mouse SmI cortex: qualitative and quantitative classification of golgi-impregnated barrel neurons. Proc Natl Acad Sci USA 72:2165-2169.

Wu CS, Ballester Rosado CJ, Lu HC (2011) What can we get from 'barrels' the rodent barrel cortex as a model for studying the establishment of neural circuits. Eur J Neurosci 34:1663-1676.

Yang JW, Hanganu-Opatz IL, Sun JJ, Luhmann HJ (2009) Three patterns of oscillatory activity differentially synchronize developing neocortical networks in vivo. J Neurosci 29:9011-9025.

Yang JW, An S, Sun JJ, Reyes-Puerta V, Kindler J, Berger T, Kilb W, Luhmann HJ (2013) Thalamic network oscillations synchronize ontogenetic columns in the newborn rat barrel cortex. Cereb Cortex 23:12991316. 